\title{
Monte Carlo-based assessment of PV impacts on real UK low voltage networks
}

DOI:

10.1109/PESMG.2013.6672620

Link to publication record in Manchester Research Explorer

\section{Citation for published version (APA):}

Navarro, A., Ochoa, L. F., \& Randles, D. (2013). Monte Carlo-based assessment of PV impacts on real UK low voltage networks. In IEEE Power and Energy Society General Meeting/IEEE Power Energy Soc. Gen. Meet. https://doi.org/10.1109/PESMG.2013.6672620

\section{Published in:}

IEEE Power and Energy Society General Meeting|IEEE Power Energy Soc. Gen. Meet.

\section{Citing this paper}

Please note that where the full-text provided on Manchester Research Explorer is the Author Accepted Manuscript or Proof version this may differ from the final Published version. If citing, it is advised that you check and use the publisher's definitive version.

\section{General rights}

Copyright and moral rights for the publications made accessible in the Research Explorer are retained by the authors and/or other copyright owners and it is a condition of accessing publications that users recognise and abide by the legal requirements associated with these rights.

\section{Takedown policy}

If you believe that this document breaches copyright please refer to the University of Manchester's Takedown Procedures [http://man.ac.uk/04Y6Bo] or contact uml.scholarlycommunications@manchester.ac.uk providing relevant details, so we can investigate your claim.

\section{OPEN ACCESS}




\title{
Monte Carlo-Based Assessment of PV Impacts on Real UK Low Voltage Networks
}

\author{
Alejandro Navarro, Graduate Student Member, IEEE, Luis F. Ochoa, Senior Member, IEEE, \\ and Dan Randles
}

\begin{abstract}
The penetration of residential photovoltaic (PV) panels is increasing particularly in those countries with special incentives. The total PV installed capacity in the UK has increased from negligible to $1.2 \mathrm{GW}$ since the Feed-In Tariff scheme was created in 2010. As a result, Distribution Network Operators (DNOs) are already experiencing voltage issues in low voltage (LV) feeders were clusters have appeared. This work proposes a Monte Carlo-based technique to assess the impacts of different PV penetrations on $L V$ networks in order to estimate their corresponding hosting capabilities. Three-phase models of two real LV networks in the North West of England are studied considering 5-min resolution synthetic data for domestic load and PV generation. Voltage-related impacts are measured using the European Standard EN50160. Additionally, the importance of data granularity on the impact assessment is analyzed. Results for the studied LV networks indicate that feeders with greater lengths and larger number of customers tend to experience voltage issues with lower PV penetration levels. In terms of the granularity, it was found that hourly resolution analyses underestimate the voltage impacts of residential PV.
\end{abstract}

Index Terms - low voltage networks, small-scale photovoltaic generation, DG impacts.

\section{INTRODUCTION}

$\mathrm{T}_{\mathrm{p}}^{\mathrm{H}}$ HE adoption of distributed energy resources, such as photovoltaic (PV) panels, electric vehicles (EVs), electric heat pumps (EHPs) and micro combined heat and power ( $\mu \mathrm{CHP}$ ), is being encouraged by many governments around the world. In particular, PV generation has received government incentives that have allowed a rapid growth. For example, the UK Government's Feed-In Tariff scheme created in 2010 has led to a total PV installed capacity exceeding 1.2 GW [1], equivalent to $1.6 \%$ of the total installed generation capacity in Great Britain. More than $75 \%$ of this PV installed capacity comes from domestic installations, i.e., small-scale $(\leq$ $4 \mathrm{~kW})$ PV systems connected to the low voltage (LV) distribution networks.

Some Distribution Network Operators (DNOs) in the UK are already experiencing voltage rise issues in $\mathrm{LV}$ feeders

This work has partly been funded by Electricity North West Limited, UK, through the Ofgem's Low Carbon Networks Fund Tier 1 Project "LV Network Solutions”, 2011-2014.

A. Navarro and L.F. Ochoa are with the School of Electrical and Electronic Engineering, The University of Manchester, Manchester M13 9PL, UK. (e-mail: alejandro.navarroespinosa-2@postgrad.manchester.ac.uk, luis_ochoa@ieee.org).

D. Randles is with Electricity North West Limited, 304 Bridgewater Place, Birchwood Park, Warrington WA3 6XG, UK. (e-mail: dan.randles@enwl.co.uk) particularly were clusters have appeared. It is in this scenario that DNOs now require tools and techniques to assess the impacts of small-scale PV generation on their LV networks. Some of the plausible impacts include: voltage rise, thermal overloads, higher levels of imbalance, higher levels of harmonics, etc. [2-3].

Several studies have been carried out in the last few years to assess the impacts of residential PV panels on distribution networks. In [4], the impacts of different DG technologies (including PV) on energy losses are analyzed. This study uses hourly resolution data and a synthetic network to carry out the assessment. The hourly approach is also adopted in [5], where it is claimed that a time step of one hour is good enough to estimate network voltages (based on previous work from the same authors [6]). On the other hand, in [7] the authors use one-minute resolution models to assess the impacts of $\mu \mathrm{CHP}$ and PV for penetrations of $30 \%$ and $50 \%$ based on the number of houses. The same approach but with a deeper PV analysis was presented in [8]. The stochastic condition of the loads and the meteorological dependence of PV generation were both addressed in [7] and [8]. However, the location and size of PV installations are considered deterministically. In [9], it was proposed the use of Monte Carlo analysis to address the stochastic nature of the interaction between loads, networks and generation. However, the study was limited to a threephase power flow algorithm able to facilitate the corresponding Monte Carlo analysis. No stochastic approach per se was developed.

Here, to adequately assess the impacts of PV on $\mathrm{LV}$ networks, it is proposed the implementation of a Monte Carlobased technique to cater for uncertainty. This technique is applied to three-phase models of two real LV networks in the North West of England considering 5-min resolution synthetic data for domestic load and PV generation. Voltage and thermal impacts are assessed for penetration levels (based on number of houses) ranging from 0 to $100 \%$. Moreover, the effect of data granularity on the computation of voltages outside statutory limits is also addressed.

This work is structured as follows: section II shows the main characteristics of the studied real LV networks. Section III explains the methodology and each step of the analysis. The main results are presented in section IV. Section V presents the sensitivity analysis corresponding to the effects of data granularity on the assessment of PV impacts. Finally, conclusions are drawn in section VI. 


\section{Accepted Paper}

\section{REAL UK LV NETWORKS}

The main advantage of working with real networks instead of synthetic ones is the possibility of capturing their particularities. For example, load unbalance, cable characteristics (direct in ground, drawn into ducts, copper conductor, etc.), network characteristics (length, number/type of customers) are all implicitly captured from real data.

Historically, DNOs have mainly worked with synthetic (or generic) LV networks in order to assess the corresponding requirements of the planning stage. Given that operational aspects are typically not considered for LV networks, it is still uncommon for DNOs to have accurate data and software packages that can be used for power flow analyses. In this work, two three-phase four-wire LV networks (Fig. 1 and Fig. 2) were modeled based on GIS data, considering the original network topology, conductor characteristics, customer locations/types and phase connectivity (when available). These LV networks are located in the North West of England, and are owned and operated by Electricity North West Limited (ENWL). Their nominal voltage is $400 \mathrm{~V}$ (line-to-line).

In Fig. 1 and Fig. 2, each color represents a different feeder and the red triangles the substations. Network 1 has four feeders, 180 costumers and $5.4 \mathrm{~km}$ of total length. Network 2 has six feeders, 428 costumers and $10.2 \mathrm{~km}$ of extension. The characteristics of each feeder are presented in Table 1.

\section{Methodology}

In general terms, the methodology consists of random allocations of load profiles for each of the costumer nodes. Then, PV generation sites (customer nodes) and sizes (0.5 to 4 $\mathrm{kW}$ ) are randomly selected (according to a given penetration). Finally, different PV profiles are allocated to generation sites. Once each feeder is populated with load and PV generation profiles, it is possible to run a power flow to assess the corresponding impacts. This generic process is repeated a hundred times for different penetration levels in order to perform a Monte Carlo analysis. This procedure is explained in detail in the following subsections.

\section{A. Domestic Load Profiles}

In order to assess the performance of LV feeders with PV it is crucial to capture the correlation (or lack of it) between demand and generation. Consequently, the time-series behavior of loads and PV generation has to be modeled.

Daily domestic load profiles used in this work have a resolution of five minutes, and have been produced based on a high resolution model for UK households (type 'domestic unrestricted') presented in [10]. The corresponding tool [11] takes into account the number of occupants, type of day (weekday or weekend), month, and appliances.

A pool of 2,000 different load profiles was adopted considering, for simplicity, only one day (weekday in September/summer). In addition, the proportion of profiles with certain number of people is based on UK statistics [12]. In this case, the proportion of houses with one person, two people, three people and four or more is $29 \%, 35 \%, 16 \%$ and $20 \%$, respectively.

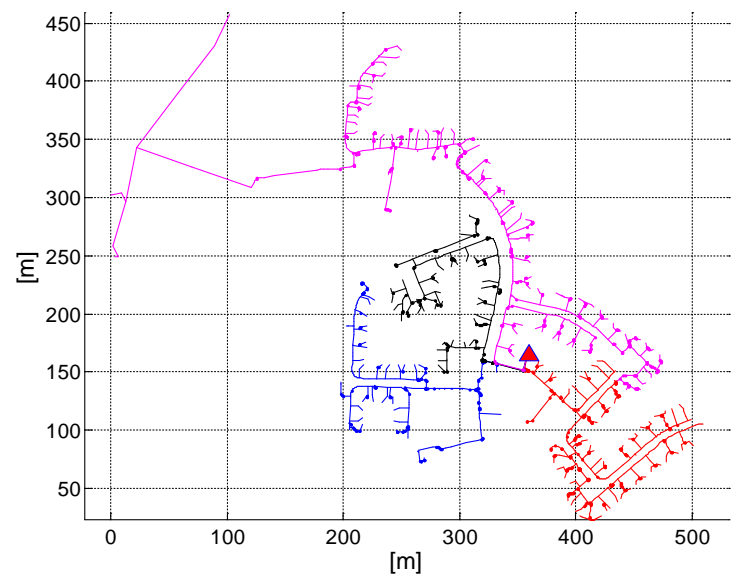

Fig. 1. Topology of LV Network 1.

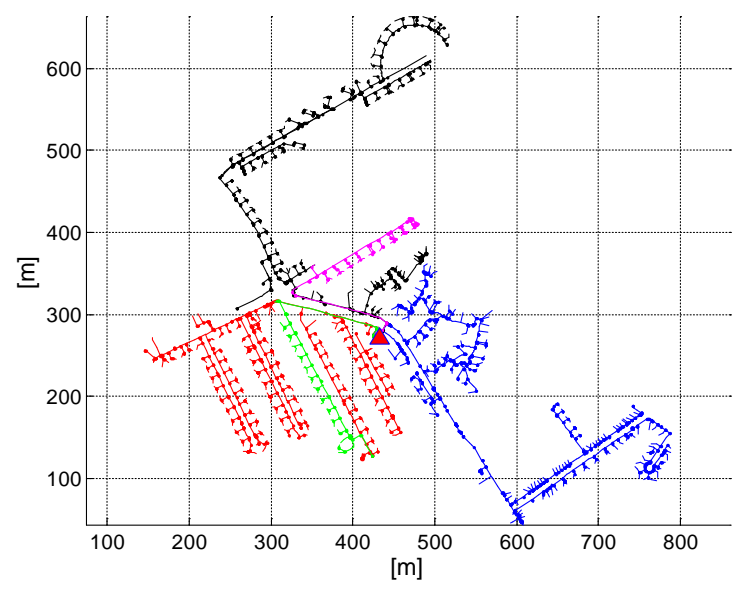

Fig. 2. Topology of LV Network 2.

TABLE 1

DISTANCE AND CUSTOMER NUMBER PER FEEDER

\begin{tabular}{c|c|c|c}
\hline LV Network & Feeder & Length $(\mathrm{m})$ & No. of Customers \\
\hline \multirow{4}{*}{1} & 1 & 1289 & 53 \\
\cline { 2 - 4 } & 2 & 920 & 26 \\
\cline { 2 - 4 } & 3 & 868 & 31 \\
\cline { 2 - 4 } & 4 & 2291 & 70 \\
\cline { 2 - 4 } & 1 & 3162 & 149 \\
\cline { 2 - 4 } & 2 & 3080 & 135 \\
\cline { 2 - 4 } & 3 & 2739 & 106 \\
\cline { 2 - 4 } & 4 & 607 & 15 \\
\hline \multirow{4}{*}{2} & 5 & 667 & 23 \\
\hline
\end{tabular}

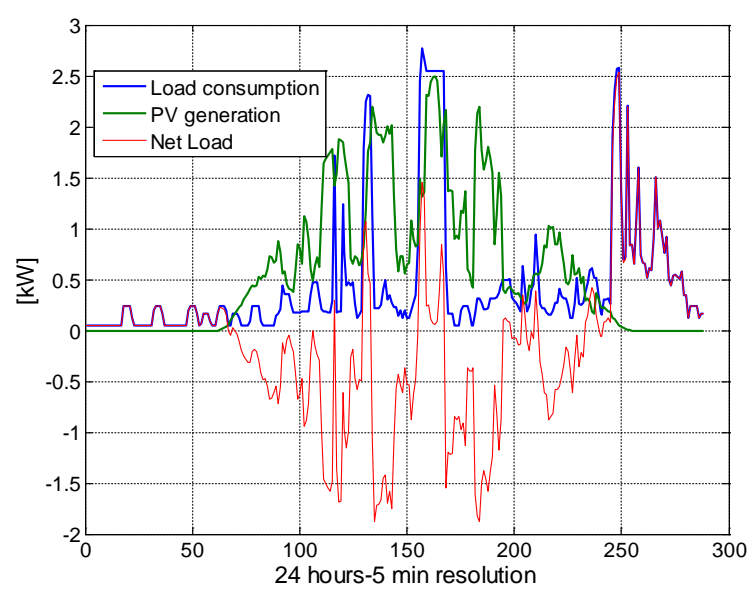

Fig. 3. Example of domestic customer with $2.5 \mathrm{~kW}$ PV generation. 


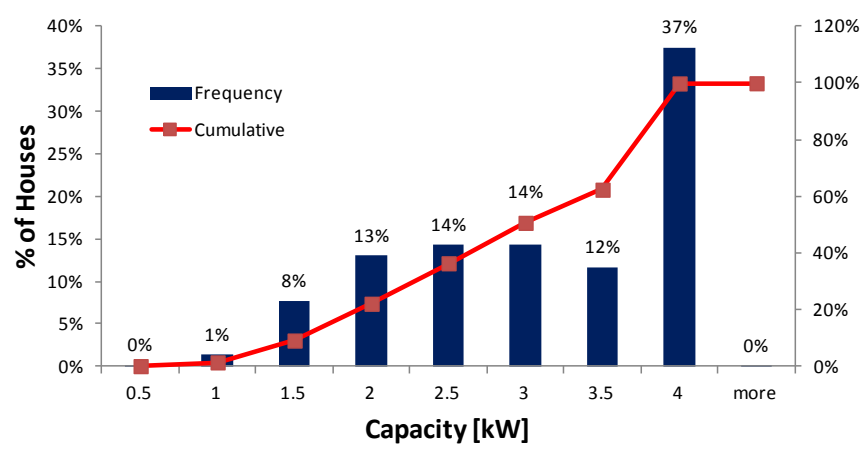

Fig. 4. Distribution of sizes (kW) of domestic PV installations in the UK [1].

The same pool of profiles also includes the corresponding irradiance. The same tool in [11] is capable of producing small-scale PV generation profiles (based on the corresponding sun irradiance) for locations in the UK [13], also considering cloud transients (Fig. 3). This is consistent with the load profile model in the sense that PV generation and electricity consumption are linked by the corresponding sun irradiance, i.e., less irradiance means less PV production and probably higher lighting usage.

The size of the PV panels to use the sun irradiance profile in each house was randomly allocated based on UK statistics for residential PV generation [1] (summarized in Fig. 4). Thus, for instance, the probability to install a PV panel of $4 \mathrm{~kW}$ is 0.37 and the probability to install a $3 \mathrm{~kW}$ panel is 0.14 .

\section{B. Monte Carlo Implementation}

With the pools of load and generation profiles it is possible to populate each feeder and run power flow simulations for different penetration levels based on number of customers/houses with PV (0 to $100 \%$ in steps of 10\%).

Given a feeder with $N$ customers and a penetration level of $P \%$, the general algorithm consists of the following stages:

1. Random selection of $N$ profiles from the load profile pool. The selection is uniform because the population already follows the distribution previously stated.

2. The selected load profiles are allocated to the customers in the feeder.

3. $\quad P \%$ of the $N$ costumers is randomly selected to have a PV panel. Each selected costumer takes exactly the same irradiance data used to create its load profile.

4. The size of each PV panel for the costumers with PV is randomly chosen using the distribution in Fig. 4.

5. With the irradiance and the size of the corresponding PV installation, the power output is calculated using [13]. This injection is modeled as PQ (negative consumption) with a power factor equal to unity.

6. Unbalance three-phase power flow analysis.

7. With the power flow results, the impact assessment is developed. The metrics associated with this stage are explained in the next subsection.

From the above procedure, it is clear that the electrical behavior of an LV network depends on a number of stochastic variables. As a result, voltages and currents will be different according to the number of people in each house, the location and size of the PV panels, etc. To capture this stochastic nature a Monte Carlo analysis is considered in this work. This process consists of running hundreds of times the algorithm presented above (stages 1 to 7 ) for each penetration level and for each feeder. The corresponding impacts are then stored for every single simulation (one penetration level, one case, 5 min) to present a probabilistic impact assessment.

\section{Impact Assessment}

An impact assessment is made for each simulation of the Monte Carlo analysis. The impacts considered in this paper are voltage rise and thermal capacity of the feeder (first line segment) and measured using the following metrics:

- Percentage of customers with voltage problems; and,

- Utilization factor of the main feeder.

The first metric takes the voltage calculated at the singlephase connection point of each customer from the power flow simulation, and checks whether the European Standard EN50160 [14] is satisfied. If not, the corresponding customer is considered to have a problem. All these cases are added up and the percentage of customers with problems is calculated.

According to the EN50160 standard, during normal conditions, voltages must be between 0.9 p.u. and 1.1 p.u. for at least $95 \%$ of data measured in a week (10 min average rms values), and never outside 0.85 p.u. and 1.1 p.u. It considers a nominal line-to-neutral voltage of $230 \mathrm{~V}$.

The second metric assesses the utilization level of the main segment of the feeder. This is calculated as the hourly maximum current through the main segment of the feeder divided by its corresponding ampacity. The current is calculated by averaging the results from the 5-min power flow simulations within each hour. This index aims to show how asset utilization behaves with different PV penetration levels.

\section{CASE STUdy}

The proposed methodology has been applied to the two LV networks presented in Section II. The algorithm runs feeder by feeder assuming a fixed line-to-neutral voltage of $240 \mathrm{~V}$ at the secondary of the transformer. The time-series three-phase four-wire power flow is solved by using OpenDSS [15].

The procedure runs one hundred times for each penetration level for every feeder. To show in detail the results of the impact assessment, feeder number 4 of LV Network 1 has been selected. Fig. 5 indicates the percentage of customers with voltage problems for each penetration level. Due to the Monte Carlo analysis, it is possible to present the average value and its deviation. For this feeder, voltage problems (according to EN50160) start at 30\% of penetration but affecting only less than $1 \%$ of the customers (i.e., less than 7 ). Considering the same feeder, a more complete visualization of the Monte Carlo analysis is presented in Fig. 6. This figure indicates for each penetration level, the percentage of customers with voltage problems and the corresponding frequency in the simulations. For instance, it can be seen that for a $40 \%$ PV penetration, $11 \%$ of loads have problems in $10 \%$ of the simulations. In other words, there is a $10 \%$ probability to have more than one tenth of customers with voltage problems with a $40 \% \mathrm{PV}$ penetration. 


\section{Accepted Paper}

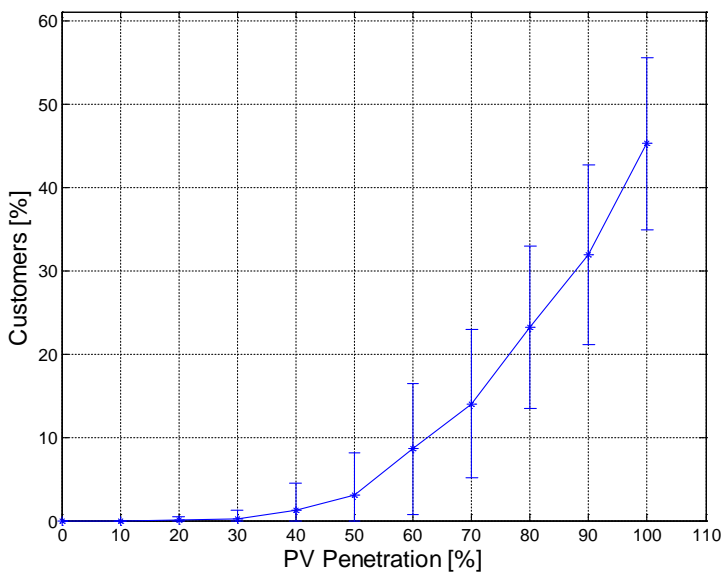

Fig. 5. Percentage of customers with voltage issues.

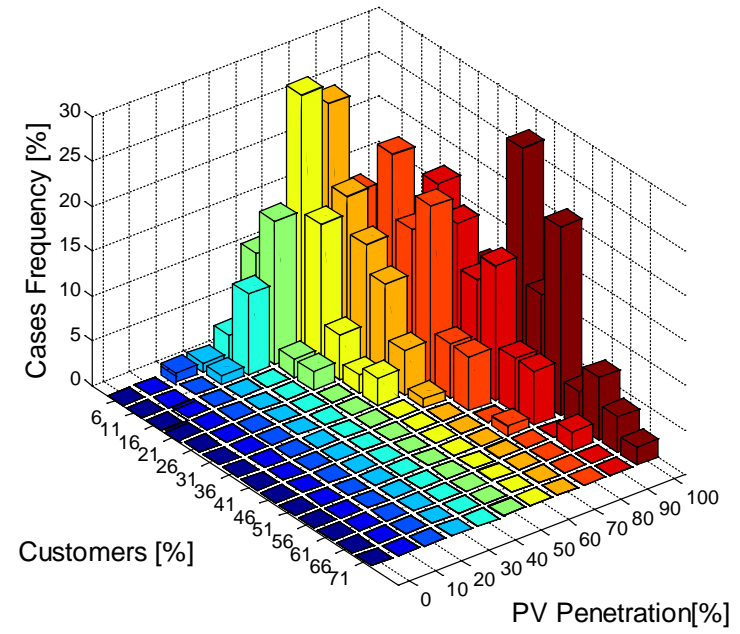

Fig. 6. Histogram of voltage issues.

The second metric for this feeder is shown in Fig. 7. It gives a good idea about how the feeder is used for the different penetration levels. The $U$ characteristic of the curve is notorious. The average utilization of the main line segment is about $80 \%$ without PV and decreases with more PV installations. This means that most of the local generation is supplying the household demand. This trend ends with a PV penetration of $50 \%$. After that point, the utilization level starts to increase with more PV installations. At $60 \%$ of PV penetration the utilization level reaches the same value as without generation; this means that the same maximum current that was imported from the grid without PV panels is now exported from the feeder. The maximum capacity is surpassed with $90 \%$ penetration of PV.

Table 2 presents the results for all the feeders of the two LV networks studied. The column Voltage Problems indicates the PV penetration level in which customers start having voltage issues. The column Utilization Level indicates the PV penetration level that results in utilization bigger than $70 \%$. This value was adopted to show potential limitations in headroom capacity for operational tasks.

While the nine feeders studied represent a very small sample of the feeders operated by the DNO, from Table 2 it is possible to observe that longer feeders (more than $1 \mathrm{~km}$ ) and those more loaded are more likely to present voltage issues at

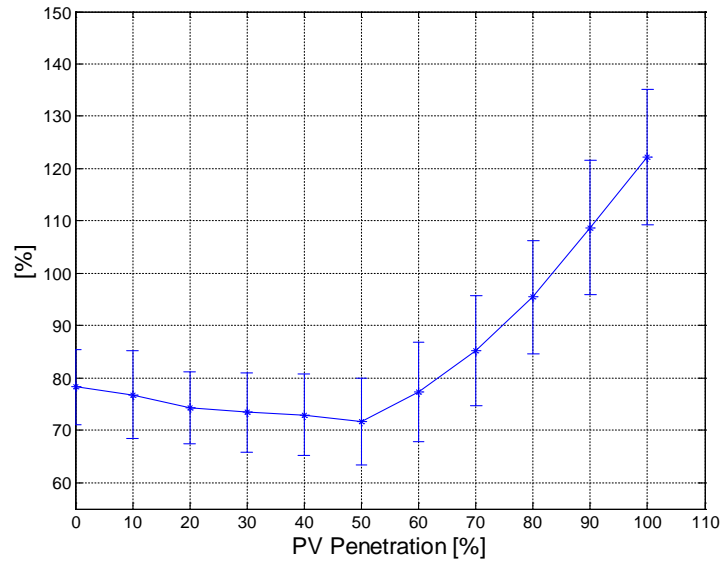

Fig. 7. Utilization of the first line segment of the feeder

TABLE 2

SUMMARY OF PV PENETRATIONS LEADING TO IMPACTS

\begin{tabular}{|c|c|c|c|c|c|}
\hline \multirow[b]{2}{*}{$\begin{array}{c}\text { LV } \\
\text { Network }\end{array}$} & \multirow[b]{2}{*}{ Feeder } & \multirow[b]{2}{*}{$\begin{array}{l}\text { Length } \\
\text { (m) }\end{array}$} & \multirow[b]{2}{*}{$\begin{array}{l}\text { No. of } \\
\text { Cust. }\end{array}$} & \multicolumn{2}{|c|}{ PV Penetration Leading to } \\
\hline & & & & $\begin{array}{c}\text { Voltage } \\
\text { Problems }\end{array}$ & $\begin{array}{c}\text { Utilization } \\
>70 \% \\
\end{array}$ \\
\hline \multirow{4}{*}{1} & 1 & 1289 & 53 & $90 \%$ & $80 \%$ \\
\hline & 2 & 920 & 26 & None & None \\
\hline & 3 & 868 & 31 & None & None \\
\hline & 4 & 2291 & 70 & $40 \%$ & $60 \%$ \\
\hline \multirow{5}{*}{2} & 1 & 3162 & 149 & $70 \%$ & $90 \%$ \\
\hline & 2 & 3080 & 135 & $20 \%$ & $90 \%$ \\
\hline & 3 & 2739 & 106 & $30 \%$ & $80 \%$ \\
\hline & 4 & 607 & 15 & None & None \\
\hline & 5 & 667 & 23 & None & None \\
\hline
\end{tabular}

some penetration level. In contrast, the feeders with few customers (less than 50 loads) do not present any voltage issue for any penetration level in the two networks analyzed.

It is also important to observe that until $20 \%$ of PV penetration there are no customers with voltage problems in all of the feeders studied.

\section{SENSITIVITY OF DATA GRANULARITY}

To analyze the effect of different data granularity in the assessment of impacts, the complete process presented previously was executed again but considering 30 and 60 minute averages for the load and PV generation profiles. For simplicity, the comparison is presented for the same example feeder (feeder 4, LV Network 1).

The average results from the Monte Carlo Analysis are presented in Fig. 8 and Fig. 9. The granularity effect is not relevant in the utilization level index, mainly because this index integrates the results in one hour. However, the effect on the calculation of voltage issues is significant due to the EN50160 requirement of $10 \mathrm{~min}$ averages. Indeed, the consideration of one hour daily profiles underestimates considerably the impacts from PV. For example, around 15\% of customers would have a voltage problem at $70 \% \mathrm{PV}$ penetration when considering $5 \mathrm{~min}$ resolution (base case). This figure goes down to about $4 \%$ when 60 min resolution is considered.

This particular analysis highlights the importance of carrying out detailed load and generation models that can actually cater for the standards used in the region of interest (in this case the EN50160). 


\section{Accepted Paper}

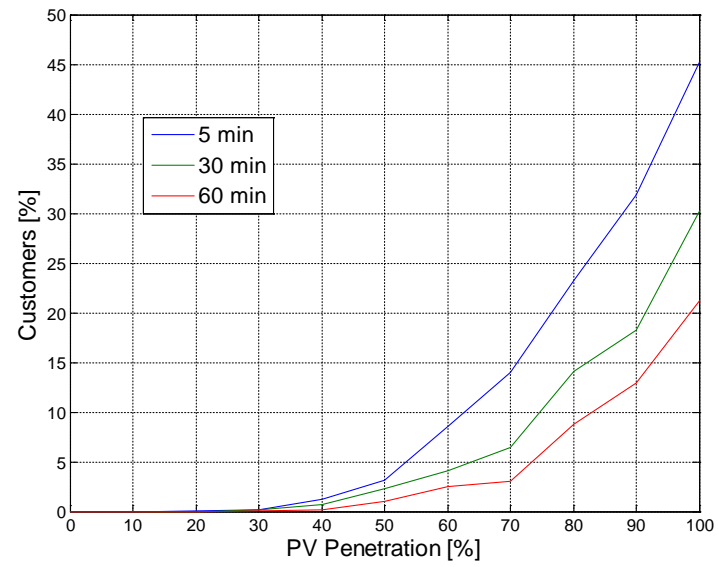

Fig. 8. Voltage problems and Data Granularity

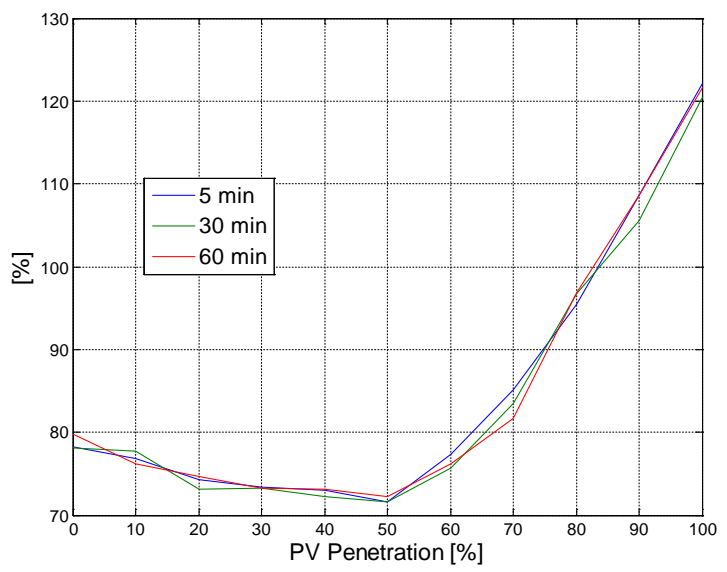

Fig. 9. Utilization level and Data Granularity

\section{CONCLUSIONS}

This work presented a Monte Carlo-based assessment of impact from small-scale PV generation on two real threephase four-wire LV networks for the North West of England. Simulations considered a 5 minute resolution for load and generation profiles and were aimed at estimating the probability of voltage rise (according to the European Standard EN50160) as well as network utilization for different PV penetration levels (based on number of customers).

The results for the nine feeders studied show that for longer or heavily loaded feeders, voltage problems can start in average at $40 \%$ of PV penetration. Small feeders, in terms of number customers (less than 35) and length (less than $1 \mathrm{~km}$ ), did not show issues for any penetration level analyzed.

The effect of data granularity on the impact assessment was also shown. It was demonstrated that hourly and half hourly approaches can significantly underestimate voltage problems that might appear due to the installation of PV panels.

\section{ACKNOWLEDGMENT}

The authors would like to thank the support of Electricity of North West Limited (ENWL) for the funding and making available the network data. Also to the Centre for Renewable Energy Systems Technology (CREST) at Loughborough University, UK, for making available the load and PV generation models used in this work.

\section{REFERENCES}

[1] UK Department of Energy and Climate Change (DECC), "Weekly solar PV installation and capacity," August, 2012.

[2] M. Begovic, I. Kim, D. Novosel, J. R. Aguero, and A. Rohatgi, "Integration of photovoltaic distributed generation in the power distribution grid," in Proc. 2011, pp. 1977-1986.

[3] L. F. Ochoa and P. Mancarella, "Low-carbon LV networks: Planning and operation challenges," in Proc. 2012 IEEE/PES General Meeting 2012, pp. 2.

[4] V. H. Méndez Quezada, J. Rivier Abbad, and T. Gómez San Román, "Assessment of energy distribution losses for increasing penetration of distributed generation," IEEE Transactions on Power Systems, vol. 21, no. 2, pp. 533-540, 2006.

[5] J. Widén, E. Wäckelgård, J. Paatero, and P. Lund, "Impacts of distributed photovoltaics on network voltages: Stochastic simulations of three Swedish low-voltage distribution grids," Electric Power Systems Research, vol. 80, no. 12, pp. 1562-1571, 2010.

[6] J. Widén, E. Wäckelgård, J. Paatero, and P. Lund, "Impacts of different data averaging times on statistical analysis of distributed domestic photovoltaic systems," Solar Energy, vol. 84, no. 3, pp. 492-500, 2010.

[7] M. Thomson and D. G. Infield, "Network power-flow analysis for a high penetration of distributed generation," IEEE Transactions on Power Systems, vol. 22, no. 3, pp. 1157-1162, 2007.

[8] M. Thomson and D. G. Infield, "Impact of widespread photovoltaics generation on distribution systems," IET Renewable Power Generation, vol. 1, no. 1, pp. 33-40, 2007.

[9] M. M. Begovic and I. Kim, "Distributed renewable PV generation in urban distribution networks," in Proc. 2011.

[10]I. Richardson, M. Thomson, D. Infield, and C. Clifford, "Domestic electricity use: A high-resolution energy demand model," Energy and Buildings, vol. 42, no. 10, pp. 1878-1887, 2010.

[11]I. Richardson and M. Thomson, "Domestic Electricity Demand ModelIntegrated Domestic Electricity Demand and PV Micro- generation Model," Loughborough University Institutional Repository, http://hdl.handle.net/2134/7773, 2010.

[12] Office for National Statistics, "Families and households, 2001 to 2011," Statistical Bulletin, January 2012.

[13] Ian Richardson and M. Thomson, "Integrated simulation of PV microgeneration and domestic electricity demand: A one_minute resolution open-source model," CREST (Centre for Renewable Energy Systems Technology), Department of Electronic and Electrical Engineering, Loughborough University., 2010.

[14]British Standards Institution, "BS EN 50160: Voltage characteristics of electricity supplied by public distribution systems," 2000.

[15]EPRI, "Open Distribution System Simulator [Online]," Available: http://sourceforge.net/apps/mediawiki/electricdss.

\section{BIOGRAPHIES}

Alejandro Navarro received the Industrial Engineer and M.Sc. degrees from the Pontificia Universidad Catolica (PUC) in Chile in 2004 and 2007, respectively. He also received a M.Sc. in Power Systems degree from The University of Manchester, UK in 2011. Currently, he is pursuing a Ph.D. in future low voltage distribution networks at The University of Manchester. Previously, he was Studies Director at Systep and lecturer at Universidad de los Andes, Chile.

Luis(Nando) Ochoa (S'01-M’07-SM'12) is a Lecturer in Smart Distribution Networks at The University of Manchester, UK. He received the B.Eng. degree from UNI, Lima, Peru, in 2000 and the M.Sc. and Ph.D. degrees from UNESP, Ilha Solteira, Brazil, in 2003 and 2006, respectively. From 2007 to 2010, he was a Research Fellow at the University of Edinburgh, UK.

His current research interests include network integration of low-carbon technologies and future distribution networks.

Dan Randles is a Technology Development Manager at Electricity North West Limited (ENWL), UK. He received the B.Eng. (Hons) degree from Liverpool John Moores University, UK, in 1996. He also received a PG Cert and a Diploma in Engineering Management from the University of Bath and the University of Bristol, respectively, in 2005 and 2011. He is currently responsible in ENWL for formulating and managing projects primarily funded by the UK Ofgem's Low Carbon Networks Fund, aimed at deploying technical and commercial innovations to ensure the transition to a low carbon economy. 